\title{
The concurrent validity of the Abilitator: a self-assessment questionnaire on functioning and work ability
}

\author{
Minna Savinainen $^{1}$ (D) Olli Jauhiainen ${ }^{2} \cdot$ Hannu Heikkilä ${ }^{3} \cdot$ Matti Joensuu $^{4}$
}

Received: 24 April 2020 / Accepted: 20 November 2020 / Published online: 11 December 2020

(C) The Author(s) 2020

\begin{abstract}
Aim The Abilitator is a self-assessment questionnaire which was developed to evaluate the perceived work ability and different aspects of functioning of working-age people. The present study aimed to explore the concurrent validity of the Abilitator.

Subject and methods The participants $(n=177)$ were patients of a rehabilitation outpatient clinic. Their mean age was 47.1 years. Using Spearman's correlation coefficients, we assessed the concurrent validity of the Abilitator to compare it to the HAD, RAND-36, EQ-5D, and WHODAS 2.0 (12-item short version) questionnaires.

Results The five domains of the Abilitator showed fair to moderate correlation coefficients with the previously validated and accepted measures of functioning. The strongest correlations were found in specific domains measuring similar constructs, namely social inclusion and RAND-36 vitality/fatigue $\left(r_{s}=0.58\right)$, psychological functioning and RAND-36 emotional wellbeing $\left(r_{s}=0.67\right)$ and HAD depression $\left(r_{s}={ }^{-} 0.65\right)$, everyday activities and total score of EQ-5D $\left(r_{s}=0.63\right)$, cognitive functioning and WHODAS 2.0 cognition $\left(r_{s}=0.57\right)$, and physical condition and RAND-36 physical functioning $\left(r_{s}=0.70\right)$. Analysis by subpopulations of gender and age group showed a broadly similar pattern to that of the total sample. In general, stronger correlations were seen among women and among those of a younger age (50 years or under).

Conclusion The Abilitator questionnaire has acceptable concurrent validity for assessing different aspects of the functioning of working-age people.
\end{abstract}

Keywords Concurrent validity $\cdot$ Functioning $\cdot$ Assessment $\cdot$ Measurement properties

\section{Introduction}

Functioning illustrates an individual's ability to take care of themselves and their household, run errands, and perform everyday tasks at home, during hobbies or studies, or at work (Hult and Lappalainen 2018). Well-being and functioning are essential to keep people in working life, as well as for social inclusion. Improving or promoting functioning and preventing work disability are important themes in both research and

Minna Savinainen

minna.savinainen@ttl.fi

1 Finnish Institute of Occupational Health, FIN-33540 Tampere, Finland

2 Department of Physiatrics, Oulu University Hospital, Oulu, Finland

3 Department of Physical Medicine and Rehabilitation Satasairaala, Pori, Finland

4 Finnish Institute of Occupational Health, FIN 00250 Helsinki, Finland practice. It is crucial that occupational rehabilitation professionals have a good insight into the different aspects of functioning and its related factors (Vendrig et al. 2018). As Vendrig et al. (2018) mentioned, medical diagnosis only plays a minor role in the actual cause of disability. Describing the level of different aspects of functioning requires the use of standardized, reliable, and valid instruments. An individual's own perception of their functioning also plays a critical role (Asante et al. 2007; Brouwer et al. 2010; Hult and Lappalainen 2018; Kevin et al. 2008; Lappalainen et al. 2017; Szlachta et al. 2012; Vastamäki et al. 2014).

Assessing functioning at working age is vital when estimating the impact of work on functioning, establishing the need for occupational rehabilitation, or measuring the effects of different interventions. Most of the functioning instruments or self-report questionnaires available for the working aged focus on some aspects of functioning, but not on total functioning (Illiffe and Pealing, 2010; Kersten et al. 2007; Knekt et al. 2008; Makowska et al. 2002; Punakallio, 2003). The Abilitator is a self-assessment questionnaire that was developed to enable the measurement of all aspects of functioning 
in the adult population, including social inclusion. The sections and the number of items of the Abilitator comprise social inclusion (12), psychological functioning (9), everyday activities (11), cognitive functioning (10), and physical condition (2). The measure of each section is a summary of the selected items. The total functioning scale is based on the mean of the individual summary scales. The multidimensional structure of the Abilitator means that occupational rehabilitation professionals can utilize it as a generic screening tool. This could diminish the need to use multiple instruments in tandem and enable professionals to focus on the specific aspects of functioning that require deeper inspection.

Validity has been defined as the extent to which an instrument assesses the true exposure of interest (Welk, 2002). This definition is frequently preferred to internal validity and implies an absolute measure of the variable being examined (Hagströmer et al. 2006). However, functioning has multidimensional exposures and it is difficult to find exact, absolute measures for them. Although the results concerning the content validity of the Abilitator have been promising (Wikström et al. 2020), the Abilitator needs further evaluation of its concurrent validity and its suitability for use in research in particular. We hypothesized that the Abilitator's social inclusion aspect would correlate strongly with the social functioning aspect of the RAND-36-item Health Survey 1.0 (RAND-36), and its psychological functioning aspect with the anxiety and depression aspects of the Hospitality Anxiety and Depression (HAD). Moreover, we hypothesized that the everyday activities aspect of the Abilitator would correlate with the EuroQol Instrument (EQ-5D) usual activities scale, its cognitive functioning aspect with the cognitive functioning (skills) aspect of the World Health Organization Disability Assessment Schedule 2.0 (WHODAS 2.0), and its physical condition aspect with the physical functioning aspect of RAND-36.

The purpose of the present study was to evaluate the concurrent validity of the Abilitator by comparing its measures with those obtained by HAD, RAND-36, EQ-5D, and WHODAS 2.0 short version in a Finnish sample of adult men and women.

\section{Methods}

\section{Participants}

The study was conducted in the outpatient clinic of the Department of Physical Medicine and Rehabilitation in Satasairaala, Finland. The rehabilitation evaluation process at the unit specializes in comprehensive evaluation, with an emphasis on determining the abilities, skills, and motivational factors for employment of individuals with deteriorated work ability due to substantial chronic medical conditions. In this study, we included all consecutive patients referred for evaluation who entered the clinic between May 2018 and May 2019. We used a sample size of 177 participants (women $n=99$ and men $n=78$ ). Their mean age was 47.1 years [range 19-61 years, standard deviation (SD) 10.4]. All questionnaires were administered to the same sample, but not all participants completed all measures, resulting in different sample sizes for different instruments. The study was approved by the Ethics Committee of the Satakunta district (SATSHP/1192/ 13.01/2018).

The individuals who entered the clinic had a history of chronic illness, mainly musculoskeletal disorders, as confirmed by a physician. Their work ability had started to deteriorate, and work disability was probable. The rehabilitation evaluation was conducted by a multi-professional team consisting of a physician, a rehabilitation counselor or social worker, a physiotherapist, an occupational therapist, and a psychologist. The main purpose of the rehabilitation evaluation was to form a comprehensive rehabilitation plan that included medical and occupational rehabilitation interventions with an emphasis on the occupational content. The final statement of the evaluation contained a work ability assessment. The practical implementation of the rehabilitation plan was the responsibility of the individuals themselves, their employee pension insurance company, and the local employment agencies.

At entry, 15 people (10\%) were working full time, 11 were working part-time (7\%), 45 (30\%) were unemployed, 60 (40\%) were on sick leave, and 18 (12\%) were receiving temporary disability pension (rehabilitation support) because of their symptoms. The average sick leave in the year preceding rehabilitation evaluation for the group was 147 days (SD 147).

This study was part of the quality register study of the Department of Physical Medicine and Rehabilitation in Satasairaala (The West Coast Quality Register). The West Coast Quality Registry uses the same questionnaires as the Swedish National Quality Registry for Pain Rehabilitation and evaluates and develops the quality of specialized pain rehabilitation clinics who treat patients with complex functional limitations requiring coordinated multimodal rehabilitation. Standardized patient surveys contain demographic data, level of education, work status and future outlook, pain intensity, psychological factors, measurements of activity/participation, and health-related quality of life [Multidimensional Pain Inventory (MPI), HAD Short Form (SF)-36, EQ-5D] (National Quality Registry for Pain Rehabilitation). All participants were requested to fill out the questionnaires at home before their first appointment at the clinic.

At the clinic, the patients were asked to estimate their functioning using the standardized International Classification of Functioning, Disability and Health (ICF) questionnaire supervised by the rehabilitation counselor, and to complete the Abilitator questionnaire by computer. The ensuing standardized rehabilitation evaluation usually took several days, after 
which the rehabilitation team met with the patient. During the occupational rehabilitation evaluation of the patients with chronic musculoskeletal disorders, their functional status was assessed systematically, and the rehabilitation team used an ICF-based assessment to present their final recommendations. The team recommendations for this group were full time work for 52 people (29\%), occupational rehabilitation for 61 people (34\%), sick leave for 33 people (19\%), partial disability pension for 22 people (12\%), and full time disability pension for 14 people $(8 \%)$.

\section{Measures}

In this study, we assessed the relationships between four similar measures of interest. To ascertain the concurrent validity of the Abilitator, a cross-sectional study was conducted that compared the measures of functioning of the Abilitator (Wikström et al. 2020) with those obtained by the HAD scale, RAND-36, EQ-5D, and WHODAS 2.0 (short version). We also wanted to determine whether the correlations differed according to gender and age group. The age groups were based on data distribution [median (Md)]: 50 years or under and over 50 years.

The Abilitator was developed in 2015-2018 as part of a European Social Fund coordination project called Social Inclusion and Changes in Work Ability and Functioning (Solmu). The Abilitator is a self-assessment method that comprises questions grouped into well-being categories, including perceived work ability and different aspects of functioning (psychological, cognitive and social functioning, physical condition, and ability to cope with everyday activities) (Wikström et al. 2020). Because it is not a diagnostic method, it has no golden standard or specific cut-off values. The questionnaire has been translated into eight languages (plain Finnish, Swedish, English, Sorani, Arabic, Somali, Russian, and Dutch) (https://sivusto.kykyviisari.fi/en/about-theabilitator/what-is-the-abilitator/).

The HAD is a self-assessment mood scale developed to identify the possible or probable caseness of anxiety disorders and depression among patients in non-psychiatric hospital clinics. Each subscale of HAD contains seven items. The anxiety and depressive subscales are valid measures of the severity of the emotional disorder (Zigmond \& Snaith 1983). HAD has been found to perform well in assessing the symptom severity and caseness of anxiety disorders and depression in somatic (Wiglusz et al. 2016), psychiatric, and primary care patients and in general populations (Bjelland et al. 2002).

The RAND-36 is perhaps the most widely used healthrelated quality of life survey instrument. It comprises 36 items that assess the eight health concepts of physical functioning, role limitations caused by physical health problems (rolephysical), role limitations caused by emotional problems (role-emotional), social functioning, emotional well-being (mental health), vitality/fatigue, pain, and general health perceptions (Hays \& Morales 2001; Wilson et al. 2005). The International Quality of Life Assessment (QOLA) project has translated and validated the 36-item Short Form Survey Instrument (SF-36) for use in 45 countries (Ware and Gandek, 1998). It is available at no cost in the public domain (Wilson et al. 2005).

The EQ-5D comprises five questions on mobility, selfcare, pain (VAS), usual activities, and psychological status and has three possible answers for each item, namely $1=$ no problem, 2 = moderate problem, $3=$ severe problem (Brooks with the EuroQol Group 1996; EuroQoL Group 1990). A summary index with a maximum score of 1 can be derived from these five dimensions by conversion with a table of scores. The maximum score of 1 indicates the best health state. In contrast, high scores in the individual questions indicate more severe or frequent problems. It also has a visual analog scale (VAS) to indicate general health status, with 100 indicating the best health status (Schrag et al. 2000).

The WHODAS 2.0 is based on the conceptual framework of the ICF and captures an individual's level of functioning in six major life domains, namely cognition (understanding and communication), mobility (ability to move and get around, self-care (ability to attend to personal hygiene, dressing and eating, and to live alone), getting along (ability to interact with other people), life activities (ability to carry out responsibilities at home, work, and school), and participation in society (ability to engage in community, civil, and recreational activities). For all six domains, the WHODAS 2.0 provides a profile and a summary measure of functioning and disability that is reliable and applicable across cultures in adult populations. In addition to the total scores, WHODAS 2.0 also makes it possible to compute domain-specific scores for cognition, mobility, self-care, getting along, life activities (at home and at work), and social participation. The short version of the WHODAS 2.0 explains $81 \%$ of the variance of the 36 -item version. For each domain, the 12-item version includes two sentinel items with good screening properties that identify over $90 \%$ of all individuals with even mild disabilities when tested on all 36 items. (Üstün et al. 2010). We did not include self-care aspects of the WHODAS 2.0 in this study, because there was no corresponding aspect in the Abilitator.

The HAD, RAND-36, EQ-5D, and WHODAS 2.0 are well developed and pretested measures. The evaluation of the strength of the correlations between the comparable variables of these measures determines the relative ability of the Abilitator to measure the same properties. To assess concurrent validity, the scales measuring similar concepts were expected to show moderate to strong correlations, while those gauging different concepts were expected to show weaker correlations (Hara et al. 2016).

The characteristics of the subjects and the outcomes of the questionnaires are described as mean and standard deviations 
(SD). The differences between genders and age groups were tested using analysis of variance (ANOVA). Concurrent validity analyses were conducted using the correlations between the Abilitator and HAD, RAND 36, EQ-5D, and WHODAS 2.0. Summary variables of the different aspects of functioning were computed from the Abilitator, HAD, RAND-36, EQ-5D, and WHODAS 2.0 to assess their association using Spearman's rho coefficients $\left(r_{s}\right)$, with particular care being taken to ensure that the computed variables were indeed comparable. The agreement coefficients were interpreted as: 0 to $0.20=$ poor, 0.21 to $0.40=$ fair, 0.41 to $0.60=$ moderate $/ \mathrm{ac}-$ ceptable, 0.61 to $0.80=$ substantial, and 0.81 to $1.0=$ near perfect (Bull et al. 2009). Data analyses used the Statistical Package for Social Sciences (SPSS version 25) program. The level of significance was set at $p<0.05$.

\section{Results}

The results of the Abilitator ( $p=0.028$ ) showed a statistically significant difference between genders in the cognitive aspects of functioning. Women had better cognitive functioning than men. The results also showed statistically significant differences between age groups. The younger age group had a better cognitive $(p=0.001)$ and physical condition $(p=0.01)$ than the older age group.

\section{The Abilitator and HAD}

In general, the agreement coefficients between the aspects of the Abilitator and HAD were statistically significant and varied from fair to substantial, except for the coefficient between physical condition and anxiety. The strongest correlations were found between psychological functioning and depression, and social inclusion and depression (see Table 1).

Among men, the strongest correlation between the Abilitator and HAD aspects were between everyday activities and anxiety $\left(\mathrm{r}_{\mathrm{s}}=-0.42\right)$ and psychological functioning and depression $\left(r_{s}=-0.63\right)$. Among women, the strongest

Table 1 Correlations $\left(r_{s}\right)$ between aspects of the Abilitator and HAD $(n=151)$

\begin{tabular}{lll}
\hline \multirow{2}{*}{ Domain } & HAD & \\
\cline { 2 - 3 } & Anxiety & Depression \\
\hline Social inclusion & $-.449 * * *$ & $-.574 * * *$ \\
Psychological functioning & $-.513 * * *$ & $-.654^{* * *}$ \\
Everyday activities & $-.373^{* *}$ & $-.469 * * *$ \\
Cognitive functioning (skills) & $-.388^{* *}$ & $-.465 * * *$ \\
Physical condition & -.157 & $-.329 * *$ \\
\hline
\end{tabular}

$* * p<.01, * * * p<.001$ correlations were found between psychological functioning and anxiety $\left(r_{\mathrm{s}}=-0.62\right)$ and, like among men, psychological functioning and depression $\left(\mathrm{r}_{\mathrm{s}}=-0.67\right)$.

The correlations between men and women in the results concerning anxiety differed to a greater extent than those concerning depression. Men had a stronger and more divergent correlation between physical condition and anxiety than women $\left(r_{s}=-0.26\right.$ vs. $r_{s}=-0.06$, respectively). Likewise, men had a stronger correlation between everyday activities and anxiety than women $\left(r_{s}=-0.42\right.$ vs. $r_{s}=-0.35$, respectively). In contrast, women had stronger correlations than men between psychological functioning and anxiety $\left(r_{s}=-0.62\right.$ vs. $r_{s}=-0.39$, respectively) and between social inclusion and anxiety ( $\mathrm{r}_{\mathrm{s}}=-0.54$ vs. $\mathrm{r}_{\mathrm{s}}=-0.32$, respectively).

Men had a stronger correlation than women between physical condition and depression $\left(r_{s}=-0.49\right.$ vs. $r_{s}=-0.22$, respectively). Women had a stronger correlation between social inclusion and depression than men $\left(r_{s}=-0.60\right.$ vs. $r_{s}=-0.44$, respectively).

The correlations between the Abilitator' different aspects of functioning and anxiety in the two age groups were almost the same. In addition, the correlation between physical condition and anxiety was the only one that was not statistically significant in both age groups.

However, the correlations between the different aspects of functioning and depression were all statistically significant among the different age groups. The strongest correlations were found between psychological functioning and depression both among the younger and the older age group $(-0.71$ vs. -0.70 , respectively).

\section{The Abilitator and RAND-36}

The strongest correlations between the Abilitator and RAND 36 aspects were between physical condition and physical functioning, psychological functioning and emotional wellbeing, and psychological functioning and vitality/fatigue. Overall, pain had the weakest correlation with the different aspects of functioning of the Abilitator (see Table 2).

The correlations between the Abilitator and RAND-36 aspects were stronger among women than among men. Among women, there were substantial correlations between physical condition and physical functioning $\left(r_{s}=0.74\right)$, the psychological functioning aspect of the Abilitator and emotional wellbeing $\left(r_{s}=0.74\right)$, vitality/fatigue $\left(r_{s}=0.67\right)$ and role limitations caused by the emotional problems aspect $\left(r_{s}=0.64\right)$ of RAND36. In contrast, the men had substantial correlations between psychological functioning and vitality/fatigue $\left(\mathrm{r}_{\mathrm{s}}=0.65\right)$ and the everyday activities and physical condition aspects of the Abilitator and physical functioning $\left(r_{s}=0.63\right.$ and $r_{s}=0.62$, respectively). Among men, the correlation between everyday activities and pain was statistically significant compared to that of 
Table 2 Correlations $\left(r_{\mathrm{s}}\right)$ between aspects of the Abilitator and RAND-36 $(n=139-145)$

\begin{tabular}{|c|c|c|c|c|c|c|c|c|}
\hline \multirow[t]{2}{*}{ Domain } & \multicolumn{8}{|l|}{ RAND-36 } \\
\hline & $\begin{array}{l}\text { Physical } \\
\text { functioning }\end{array}$ & Role -physical & Role- emotional & $\begin{array}{l}\text { Social } \\
\text { functioning }\end{array}$ & $\begin{array}{l}\text { Emotional } \\
\text { well-being }\end{array}$ & Vitality/ fatigue & Pain & $\begin{array}{l}\text { Health } \\
\text { perception }\end{array}$ \\
\hline Social inclusion & $.185^{*}$ & .186 & $.470 * * *$ & $.442 * * *$ & $.519 * * *$ & $.579 * * *$ & .106 & $.420 * * *$ \\
\hline $\begin{array}{r}\text { Psychological } \\
\text { functioning }\end{array}$ & $.202 *$ & $.225^{*}$ & $.556 * * *$ & $.472 * * *$ & $.673^{* * *}$ & $.662 * * *$ & .114 & $.461 * * *$ \\
\hline Everyday activities & $.574 * * *$ & $.371 * * *$ & $.310^{* * *}$ & $.405^{* * *}$ & $.427 * * *$ & $.457 * * *$ & $.268 * * *$ & $.402 * * *$ \\
\hline $\begin{array}{l}\text { Cognitive functioning } \\
\text { (skills) }\end{array}$ & $.307 * * *$ & $.198 *$ & $.361 * * *$ & $.307 * * *$ & $.503 * * *$ & $.536 * * *$ & $.195 *$ & $.384 * * *$ \\
\hline Physical condition & $.697 * * *$ & $.304 * * *$ & .166 & $.322 * * *$ & $.213 *$ & $.288 * * *$ & $.236 * *$ & $.304 * * *$ \\
\hline
\end{tabular}

$* p<.05, * * p<.01, * * * p<.001$

the women, whose correlation was weaker and not statistically significant $\left(r_{s}=0.44\right.$ vs. $r_{s}=0.13$, respectively).

In the younger age group, there were stronger correlations between the different aspects of the Abilitator and those of RAND-36 than in the older age group. There were also substantial correlations between physical condition and physical functioning ( $r_{s}=0.70$ vs. $r_{s}=0.64$, respectively), the psychological functioning aspect of the Abilitator and vitality/fatigue $\left(r_{s}=0.70\right.$ vs. $r_{s}=0.61$, respectively), and emotional well-being $\left(r_{s}=0.69\right.$ vs. $r_{s}=0.63$, respectively). In addition, the younger age groups had substantial correlations between social inclusion and the vitality/fatigue aspect of RAND-36 $\left(r_{s}=0.68\right)$.

\section{The Abilitator and EQ-5D}

In general, the agreement coefficients between the Abilitator and EQ-5D varied from poor to substantial. The strongest, most substantial correlations were between everyday activities and total EQ-5D $\left(r_{s}=0.63\right)$ and between physical condition and EQ-mobility $\left(r_{s}=-0.62\right)$. EQ-VAS (pain) and total EQ$5 \mathrm{D}$ were aspects that correlated statistically significantly with all aspects of the Abilitator (see Table 3).

The strongest correlations among women were between everyday activities and EQ-5D, and among men between physical condition and EQ-mobility. The strongest correlations in the younger age group were between physical condition and mobility, and in the older age group between everyday activities and total EQ-5D score.

\section{The Abilitator and WHODAS 2.0}

Most of the correlations between the aspects of the Abilitator and those of the WHODAS 2.0 (short version) were statistically significant, except for those between physical condition and social participation, physical condition and cognition, and between social inclusion and life activities (see Table 4).
There were more statistically significant correlations between the aspects of the Abilitator and WHODAS 2.0 among women than among men. However, among both women and men, the variation in the correlations was almost the same $\left(r_{s}=0.08-0.59\right.$ vs. $r_{s}=0.07-0.59$, respectively). The strongest, albeit moderate, correlations among women were between the cognitive functioning aspect of the Abilitator and the cognition aspect of WHODAS 2.0, whereas among men the strongest correlation was noted between the everyday activities aspect of the Abilitator and the mobility aspect of WHODAS 2.0.

\section{Summary of the results}

As expected, the highest correlation coefficients were in the specific domains measuring similar constructs.

Different instruments correlated with the different aspects of functioning of the Abilitator. The social inclusion aspect of the Abilitator correlated the most with the RAND-36 aspect of vitality/fatigue $\left(r_{\mathrm{s}}=0.58\right)$. The psychological functioning aspect of the Abilitator correlated the most strongly with the emotional well-being aspect of RAND-36 $\left(r_{\mathrm{s}}=0.67\right)$ and with the depression subscale of $\operatorname{HAD}\left(\mathrm{r}_{\mathrm{s}}={ }^{-} 0.65\right)$. The everyday activities aspect of the Abilitator correlated with the total score of the EQ-5D $\left(r_{s}=0.63\right)$. A moderate correlation was found between the cognitive functioning aspect of the Abilitator and the cognition aspect of WHODAS $2.0\left(r_{\mathrm{s}}=0.57\right)$. The physical condition aspect of the Abilitator correlated substantially with the physical functioning aspect of RAND-36 $\left(r_{s}=0.70\right)$. Analysis by the sub-populations of gender and age group for all questionnaires showed a broadly similar pattern to that of the total sample. In general, stronger correlations were seen among women and among the younger age group than among men and the older age group. 
Table 3 Correlations $\left(\mathrm{r}_{\mathrm{s}}\right)$ between aspects of the Abilitator and EQ-5D $(n=142-147)$

\begin{tabular}{lllllll}
\hline Domain & EQ-mobility & EQ-self-care & EQ-VAS (pain) & EQ-usual activities & EQ- psychological status & Total EQ-5D \\
\hline Social inclusion & -.097 & -.092 & $.239 * *$ & -.128 & $-.423^{* * *}$ & $.371^{* * *}$ \\
Psychological functioning & $-.167 *$ & $-.180^{*}$ & $.248^{* *}$ & -.117 & $-.373^{* * *}$ & $.424 * * *$ \\
Everyday activities & $-.445^{* * *}$ & $-.414 * * *$ & $.397 * * *$ & $-.436^{* * *}$ & $-.274 * * *$ & $.633^{* * *}$ \\
Cognitive functioning (skills) & -.165 & $-.232^{*}$ & $.244^{* *}$ & $-.169^{*}$ & $-.302^{* * *}$ & $.417 * * *$ \\
Physical condition & $-.615^{* * *}$ & $-.438^{* * *}$ & $.436^{* * *}$ & $-.408^{* * *}$ & -.064 & $.542 * * *$ \\
\hline
\end{tabular}

$* p<.05, * * p<.01, * * * p<.001$

\section{Discussion}

The present study examined the concurrent validity of the Abilitator. The results showed fair to moderate agreement with the external criteria (HAD, RAND-36, EQ-5D, and WHODAS 2.0 the short version). We hypothesized that the social inclusion aspect of the Abilitator would correlate strongly with the social functioning aspect of RAND-36, the psychological functioning aspect of the Abilitator with the anxiety and depression aspect of HAD, the everyday activities aspect of the Abilitator with EQ-usual activities, the cognitive functioning aspect of the Abilitator with the cognition aspect of WHODAS 2.0, and the physical condition aspect of the Abilitator with the physical functioning aspect of RAND-36. The Abilitator features correlated the most with the RAND 36 measures of the social, psychological, and physical aspects of functioning. The psychological functioning aspect of the Abilitator also correlated strongly with the depression subscale of HAD, but to a slightly lesser extent with anxiety. In relation to the cognitive aspect of functioning, the Abilitator had the strongest correlation with the cognition aspect of WHODAS 2.0. In addition, regarding everyday activities, we found the strongest correlation between the Abilitator and EQ-5D. Some differences were seen in the sub-analyses of gender and age group. In general, the coefficients were stronger among women and the younger age group than men and the older age group.
Overall, the Abilitator showed a fair to moderate correlation with the previously validated and accepted measures of functioning and well-being. Some of the coefficients were substantial, depending on the instruments and different aspects of functioning, which suggests that although the Abilitator and the other recognized instruments have similar constructs, the Abilitator also measures something different. For example, HAD is used as a diagnostic measure, which is not the purpose of the Abilitator. The correlation coefficients obtained indicate that the Abilitator measures what it aims to measure, i.e., different aspects of functioning.

Several factors may be responsible for these findings, including the differences in the concepts of overall functioning, different scoring methods (Wilson et al. 2005), and different ways of framing general functioning. The instruments varied in terms of the questions, for example, in the time modifier (How do you perceive your situation in general or during the last 30 days?), and in the way the different options were presented, such as differentiated levels of agreement (totally agree-totally disagree) or with more emphasis on problems (no problem-unable to do something) or how the respondent perceived the situation in general or compared to others. Investigators should not rely simply on the names of the questionnaires and their subscales or domains; they should also consider the content and structure of the individual items (Wilson et al. 2005). Although the subscales of the Abilitator and other measure addressing different aspects of

Table 4 Correlations $\left(\mathrm{r}_{\mathrm{s}}\right)$ between aspects of the Abilitator and WHODAS $2.0(n=157-160)$

\begin{tabular}{lllllll}
\hline Domain & \multicolumn{2}{l}{ WHODAS 2.0 (12-item short version) } & & \\
\cline { 2 - 7 } & \multicolumn{1}{l}{ Social participation } & Getting along & Life activities & Cognition (skills) & Mobility & Total WHODAS 2.0 \\
\hline Social inclusion & $.243^{* *}$ & $.365^{* * *}$ & .123 & $.286^{* * *}$ & $.160^{*}$ & $.255^{* * * *}$ \\
Psychological functioning & $.255^{* * *}$ & $.474 * * *$ & $.198^{*}$ & $.396^{* * *}$ & $.296^{* * *}$ & $.363^{* * *}$ \\
Everyday activities & $.261^{* * *}$ & $.424 * * *$ & $.422^{* * *}$ & $.391^{* * *}$ & $.505^{* * *}$ & $.525^{* * *}$ \\
Cognitive functioning (skills) & $.372^{* * *}$ & $.460^{* * *}$ & $.290^{* * *}$ & $.565^{* * *}$ & $.272^{* * *}$ & $.454^{* * *}$ \\
Physical condition & .090 & $.343^{* * *}$ & $.428^{* * *}$ & .135 & $.556^{* * *}$ & $.450^{* * *}$ \\
\hline
\end{tabular}

$* p<.05, * * p<.01, * * * p<.001$ 
functioning (e.g., RAND-36) appear to gauge similar dimensions of functioning, the subscales and overall scores are not interchangeable.

Defining and measuring disability is challenging. The World Health Organization (WHO) has tried to address this problem by establishing the ICF international classification scheme (World Health Organization 2001.) Üstün et al. (2010) emphasize that all standard instruments for measuring disability and health need to be linked both conceptually and operationally to the ICF to allow comparisons across different cultures and populations. The content of the Abilitator has been linked to ICF codes to enable these juxtapositions (Wikström et al. 2020).

\section{Strengths and limitations}

We used multiple instruments in assessing the concurrent validity of the Abilitator. These tools are widely used, and their specific items/domains correlated strongly with the different aspects of functioning. It was useful to consider different subgroups instead of only analyzing the total sample, because the results varied somewhat depending on the gender and age group. The participants of this study were aged between 19 and 61 years of age, which was in line with the population for whom the Abilitator questionnaire was designed/developed.

On the other hand, the small sample size within certain groups (e.g., men $n=78$ ) limited our ability to draw definitive conclusions and the generalization of our study findings is limited since it was restricted to a specific population of patients in the outpatient clinic of the Department of Physical Medicine and Rehabilitation. In addition, we had no objective measures for assessing concurrent validity. The clinic also uses different health-related measures to assess functioning, such as a walking test. However, most of the participants of this study had contraindications, mainly because of poor health (e.g., cardiac conditions), which made the sample size too small for these measures to be included in the analyses.

\section{Practical implications and further research}

Based on this study, the Abilitator can be used as a selfassessment method for evaluating different aspects of functioning. It is a generic tool and suitable for examining the general functioning of an individual and highlighting the aspects of functioning that need further or deeper focus. More studies, conducted on larger samples of different populations and in prospective settings, are needed to strengthen the usefulness and interpretation of the Abilitator. Future studies should also examine the differences found between men and women and/or different age groups in more detail.

\section{Conclusion}

We evaluated the concurrent validity of the Abilitator and HAD, RAND-36, EQ-5D, and WHODAS 2.0 (short version). The correlations between the different measures of similar concepts were moderate, indicating that the instruments focus on the same aspects of functioning. Our results showed that the Abilitator had acceptable concurrent validity for assessing different aspects of functioning among working-age people.

Acknowledgments The authors would like to thank Elina Lindgren (rehabilitation counsellor) and Tiia Vuori (psychologist) for their excellent work during data collection. The Abilitator questionnaire was developed as part of the Social Inclusion and Change in Work Ability and Functioning (Solmu) co-ordination project of the Finnish Institute of Occupational Health, which is funded by the European Social Fund (1.10.2014-30.9.2020).

Funding This study was funded by the European Social Fund (ESF) (Grant Number EURA 2014/540/09 0201 01/2014/STM) via the project, "Social Inclusion and Change in Work Ability and Functional Capacity."

\section{Compliance with ethical standards}

Ethical approval All procedures followed were in accordance with the ethical standards of the responsible committees on human experimentation (institutional and national) and with the Helsinki Declaration of 1964, as revised in 2018 [https://www.wma.net/policies-post/wma-declarationof-helsinki-ethical-principles-for-medical-research-involving-humansubjects/ Accessed 30 April 2019].

Informed consent Informed consent was obtained from all patients included in the study.

Conflict of interest The authors declare that they have no conflict of interest.

Open Access This article is licensed under a Creative Commons Attribution 4.0 International License, which permits use, sharing, adaptation, distribution and reproduction in any medium or format, as long as you give appropriate credit to the original author(s) and the source, provide a link to the Creative Commons licence, and indicate if changes were made. The images or other third party material in this article are included in the article's Creative Commons licence, unless indicated otherwise in a credit line to the material. If material is not included in the article's Creative Commons licence and your intended use is not permitted by statutory regulation or exceeds the permitted use, you will need to obtain permission directly from the copyright holder. To view a copy of this licence, visit http://creativecommons.org/licenses/by/4.0/.

\section{References}

Asante AK, Brintnell ES, Gross DP (2007) Functional self-efficacy beliefs influence functional capacity evaluation. J Occup Rehabil 17: 73-82. https://doi.org/10.1007/s10926-007-9068-1

Bjelland I, Dahl AA, Haug TT, Neckelmann D (2002) The validity of the hospital anxiety and depression scale: an updated literature review. J 
Psychosom Res 52(2):69-77. https://doi.org/10.1016/S0022-3999(01) 00296-3

Brooks R with the EuroQol Group (1996) EuroQol: the current state of play. Health Policy 37:53-72

Brouwer S, Reneman MF, Bültmann U et al (2010) A prospective study of return to work across health conditions: perceived work attitude, self-efficacy and perceived social support. J Occup Rehabil 20:104 110. https://doi.org/10.1007/s10926-009-9214-z

Bull FC, Maslin TS, Armstrong T (2009) Global physical activity questionnaire (GPAQ): nine country reliability and validity study. J Phys Act Health 6(6):790-804. https://doi.org/10.1123/jpah.6.6.790

EuroQoL Group (1990) EuroQoL: a new facility for the measurement of health-related quality of life. Health Policy 16:199-208

Hagströmer M, Oja P, Sjöström M (2006) The International Physical Activity Questionnaire (IPAQ): a study of concurrent and construct validity. Public Health Nutr 9(6):755-762. https://doi.org/10.1079/ PHN2005898

Hara N, Matsudaira K, Masuda K, Tohnosu J, Takeshita K, Kobayashi A et al (2016) Psychometric assessment of the Japanese version of the Zurich Claudication Questionnaire (ZCQ): reliability and validity. PLoS One 11(7):e0160183. https://doi.org/10.1371/journal.pone.0160183

Hays RD, Morales LS (2001) The RAND-36 measure of health-related quality of life. Ann Med Jul 33(5):350-357. https://doi.org/10.3109/ 07853890109002089

Hult M, Lappalainen K (2018) Factors associated with health and work ability among long-term unemployed individuals. Int J Occup Health Public Health Nurs 5(1):5-22

Illiffe S, Pealing L (2010) Subjective memory problems. BMJ 340:703-706

Kersten P, Cardol M, George S, Ward C, Sibley A, White B (2007) Validity of the impact on participation and autonomy questionnaire. A comparison between two countries. Disabil Rehabil 29:1502-1509

Kevin N, Alschuler ME, Theisen-Goodvich AJ, Haig M, Geisser E (2008) A comparison of the relationship between depression, perceived disability, and physical performance in persons with chronic pain. Eur J Pain 12(6):757-764. https://doi.org/10.1016/j.ejpain.2007.11.003

Knekt P, Lindfors O, Härkänen T et al (2008) Randomized trial on the effectiveness of long-and short-term psychodynamic psychotherapy and solution-focused therapy on psychiatric symptoms during a 3year follow-up. Psychol Med 38(5):689-703

Lappalainen K, Manninen P, Räsänen K (2017) Association among sociodemographic factors, work ability, health behavior, and mental health status for young people after prolonged unemployment. Workplace Health Saf 65(2):65-73. https://doi.org/10.1177/ 2165079916653767

Makowska Z, Merecz D, Moscicka A, Kolasa W (2002) The validity of general health questionnaires, GHQ-12 and GHQ-28, in mental health studies of working people. Int J Occup Med Environ Health 15(4):353-362

Punakallio A (2003) Balance abilities of different-aged workers in physically demanding jobs. J Occup Rehabil 13:33-43
Schrag A, Selai C, Jahanshahi M, Quinn NP (2000) The EQ-5D - a generic quality of life measure - is a useful instrument to measure quality of life in patients with Parkinson's disease. J Neurol Neurosurg Psychiatry 69(1):67-73. https://doi.org/10.1136/jnnp.69.1.67

Szlachta E, Gawlik-Chmiel B, Kallus KW (2012) Do the long-term unemployed regard themselves as able to work? J Public Health 20: 505-511. https://doi.org/10.1007/s10389-012-0505-Z

Üstün TB, Chatterji S, Kostanjsek J, Kennedy C, Epping-Jordan J, Saxena S, von Korff M, Pull C in collaboration with WHO/NIH Joint Project (2010) Developing the World Health Organization disability assessment schedule 2.0. Bull World Health Organ 88: 815-823. https://doi.org/10.2471/BLT.09.067231

Vastamäki J, Wolff H, Paul KI, Moser K (2014) Sense of coherence mediates the effects of low work ability on mental distress during unemployment. J Work Behav Health 29(4):317-332. https://doi. org/10.1080/15555240.2014.956931

Vendrig L, Wijnvoord L, Schaafsma FJ (2018) Reliability and validity of the work and well-being inventory (WBI) for self-employed workers: test norms of employees are not suitable for entrepreneurs. J Occup Rehabil 29:595-608. https://doi.org/10.1007/s10926-018-9821-7

Ware JE, Gandek B (1998) Overview of the SF-36 health survey and the international quality of life assessment (IQOLA) project. J Clin Epidemiol 51:903-912

Welk G (2002) Physical assessment in health-related research. Human Kinetics, Leeds

Wiglusz MS, Landowski J, Michalak L, Cubala WJ (2016) Validation of the hospital anxiety and depression scale in patients with epilepsy. Epilepsy Behav 58:97-101. https://doi.org/10.1016/j.yebeh.2016.03.003

Wikström M, Anttila H, Savinainen M et al (2020) Development and content validity of the Abilitator: a self-report questionnaire on work ability and functioning aimed at the population in a weak labour market position. BMC Public Health 20(327). https://doi.org/10. 1186/s12889-020-8391-8

Wilson RW, Hutson LM, VanStry D (2005) Comparison of 2 quality- of life questionnaires in women treated for breast cancer: the RAND 36-item health survey and the functional living index-cancer. Phys Ther 85(9):851-860

World Health Organization (2001) International classification of functioning, disability and health. WHO, Geneva

Zigmond AS, Snaith RP (1983) The hospital anxiety and depression scale. Acta Psychiatr Scand 67:361-370

Author contributions All authors contributed to the study conception and design. Material preparation, data collection and analysis were performed by Hannu Heikkilä and Olli Jauhiainen. The first draft and revision of the manuscript was written by Minna Savinainen and all authors commented on the manuscript. All authors read and approved the final manuscript.

Publisher's note Springer Nature remains neutral with regard to jurisdictional claims in published maps and institutional affiliations. 